\title{
COVID-19 Between Panic and Confrontation as a Step Towards Psychological Counselling: A Case Study of Faculty of Education Students of Helwan University
}

\author{
Salwa Mohamed Abdel Baky', Khaled Mohamed Fargoun ${ }^{2}$, \\ Fatma Elzahraa Abdel Basit Abdel Wahed ${ }^{1, *}$ \\ ${ }^{1}$ Department of Mental Health, Faculty of Education, Helwan University, Cairo, Egypt \\ ${ }^{2}$ Department of Educational Technology, Faculty of Education, Helwan University, Cairo, Egypt
}

Email address:

fatma_abdelbasit@yahoo.com (F. E. A. B. A. Wahed)

${ }^{*}$ Corresponding author

\section{To cite this article:}

Salwa Mohamed Abdel Baky, Khaled Mohamed Fargoun, Fatma Elzahraa Abdel Basit Abdel Wahed. COVID-19 Between Panic and Confrontation as a Step Towards Psychological Counselling: A Case Study of Faculty of Education Students of Helwan University. Psychology and Behavioral Sciences. Vol. 10, No. 1, 2021, pp. 39-48. doi: 10.11648/j.pbs.20211001.15

Received: January 7, 2021; Accepted: January 14, 2021; Published: January 28, 2021

\begin{abstract}
The worldwide panic over the spread of the Corona virus, all over the world, has made it a responsibility for researchers to research how to respond to the crisis and find effective mechanisms for positive dealing with it. Thus this paper aimed to identify the negative repercussions that have occurred due to the emergence of Corona-virus and the panic that ensued. Therefore the research objected to identify the reactions of university students towards this crisis and the ways of confrontation. Researchers wanted also to be informed about the students with high degrees of panic in order to design a mentoring program that may help such students deal with their panic. A test of Coping with COVID-19 Crisis and a test of Panic were applied to a sample of the faculty of education students. The results showed that about $44 \%$ of them were suffering from panic and in need of psychological health care. Most students used all of coping strategies and especially the Affective and the behavioral. Results showed highly significant difference, where female students were much more in panic compared to male students. We can predict the score of style of coping by knowing the score of panic. In conclusion, panic is negatively associated with strategies of confrontation, so the study recommends supporting positive coping strategies for individuals within crises.
\end{abstract}

Keywords: Panic Disorder, Coping, Coping Strategies, Coping Strategy, Crises, Pandemic

\section{Introduction}

A few days after learning about the news of corona virus, Fatma Abdel Basit, a colleague in the mental health department called Salwa Abel Baky and discussed with her the possibility of conducting a research about panic that is accompanying the emergence of the crisis and the importance of recognizing it. She offered to participate and as Salwa was agreeable, the latter asked Khalid Fargon to participate and the three started the procedures. The preliminary results have been already discussed and now this is the final report.

\subsection{Premise}

Facing a pandemic like COVID-19, people usually feel that they are fighting an invisible enemy. Therefore, it was expected that most people to be in a state of anxiety. However, scientists know very well that there are individual differences meaning that there are minorities that may be extremely terrified. So Researchers must pay attention to the importance of rapid intervention in order to remedy the terror in this group, especially when they are youth that is the most important group in society. As youth are the future of the world, no one should ignore how serious this situation is.

\subsection{Research Problem}

When people around the world faced the crisis of coronavirus, measures of confrontation varied from one country to another. As the world, thanks to the internet, has become a small one, countries of the third world have known about 
Europe and America and the huge numbers of infections there. The emergence of cases in Egypt caused researchers in the field of mental health to take positive steps towards the study of the level of prevalence of panic as well as the reactions of people to the crisis. In addition to the study of the pattern of confrontation of the crisis, the problem of the current research is related to the problem of youth of the university and their trending reactions. The identification of the patterns of confrontation of the crisis allows the design of a counseling program that treats students of the Faculty of Education, as a youth category that represents the real wealth of any society.

\section{Research Objectives}

The current research objectives are to find out the following:

1) How common is panic and fright among the students of the Faculty of Education as a result of corona virus crisis.

2) The difference between males and females on the score of panic.

3) The differences of reactions of students of different grades towards corona virus crisis.

4) The relation between panic and the patterns of students' coping with corona virus crisis.

5) Who are suffering from panic and are in need of intervention.

6) The effect of human developmental training courses on coping.

7) The effect of social media on the feeling of panic.

8) The possibility to predict the level of coping from a known level of panic.

As said earlier. we don't hypothesize about any of these objectives, letting data and analysis tell us the story.

\section{Conceptual Framework \& Literature}

\subsection{Horror Through History}

Throughout history, disease outbreaks have ravaged humanity to the point that sometimes it changed the course of history and at times it signaled the end of an entire civilization. Remaining in human memory, this may be a source of horror. To cite examples, about 5.000 years ago, a prehistoric village in China was wiped out. Archaeological and anthropological study indicates that the epidemic happened quickly enough that there was no time for proper burials, and the site was not inhabited again. Concerning pandemics, the earliest recorded one around 430 B.C. lasted for 5 years passing through the walls of Athens that were besieged by the Spartans killed about 100,000 of the Athenian population. This was a very large number compared to the total population at the time. In 1 about 500 millions 65 A.D. a plague was brought to Rome by Roman troops returning from war and was spread to the whole Roman Empire. It killed more than 5 millions including and has ended the Roman Peace. After it instability and civil wars grew in the empire. More recently, in 1918-1920 the Spanish Flu spread worldwide infecting 500 millions claiming the lives of one fifth of them [1].

Recently, In January 2020 the World Health Organization (WHO) declared the outbreak of a new coronavirus disease, to be a Public Health Emergency of International Concern. WHO stated that there is a high risk of COVID-19 spreading to other countries around the world. In March 2020, WHO made the assessment that COVID-19 can be characterized as a pandemic [2].

\subsubsection{Conceptualization}

Panic disorder is a type of anxiety disorder that is characterized by fear and worry. One of the most salient symptoms is the experience of persistent and often unanticipated combination of fear, physical sensations and distressing thoughts and emotions. Panic disorders are diagnosed in this research as occurring as result of Corona virus infection. This virus can infect both animals and humans and can cause a form of respiratory illness that is different from and more dangerous than the common cold. This results in conditions of severely acute respiratory syndrome or SARS. It is known that this virus is much more transmissible than SARS or MERS (Middle East Respiratory Syndrome) and that it can kill people.

\subsubsection{Cognitive Models of Panic Disorder}

Psychologists have a long record of interest in issues relating to fear and anxiety. A logical extension of this was the development of cognitive models of panic disorder. Two of the earliest theories were actually developed independently but at roughly the same time. Clark [3], and Barlow [4] developed models with a good degree of conceptual overlap that calls for explanation.

\subsubsection{Clarke's Cognitive Model of Panic}

David Clarke coined the phrase "catastrophic misinterpretations" in order to describe the bodily sensations experienced by people who panic. Palpitations, for example, are prone to being misinterpreted as a heart attack and dizziness may be a sign of imminent collapse or loss of control. Thus, Clarke suggests that misinterpretation of bodily sensations is the cause of panic events and that changes in bodily sensations usually preceded an episode of panic. Once catastrophic misinterpretation is triggered, he argues, the likelihood of panic increases.

Various lines of evidence seem to support Clarke's views. We now know that patients with panic disorder have higher frequencies of cognition that lend themselves to catastrophic misinterpretations. Some of the clearest evidence come from cases where panic events stop once the patient's cognition has been altered.

\subsubsection{Learned Alarm Reaction (False Alarm Theory)}

This is Barlow's approach, which is often described as an integrated model because it attempts to link biological and cognitive functions. Barlow suggests that certain people are 
"hard-wired" from birth to react to certain stressful events. What makes these people different is their tendency towards overreaction. The ability to discriminate between true and false alarms is blurred and in some people the false alarm becomes a conditioned response to the bodily sensations associated with anxiety. This model shares many similarities with Clarke's as to the manner in which bodily sensations are interpreted. Various studies show as support for his theory that negative life events often precede the first panic attack. However, stress is not a unique precursor to panic as it is known to precede other psychological conditions.

\subsubsection{Anxiety Sensitivity Theory}

Anxiety sensitivity refers to the fear of anxiety sensations and the belief that such sensations have harmful physical and/or psychological consequences. This form of cognitive vulnerability is considered to be a specific sensitivity to respond fearfully to one's own sensations. It is considered as possibly may put people at greater risk of developing anxiety disorders, especially panic disorder of agoraphobia. One characteristic of panic disorder is high levels of anxiety sensitivity, characterized by high levels of vigilance to one's own bodily sensations that signal a threat. Depression and bipolar disorders are associated with anxiety sensitivity.

\subsection{Confrontation}

Confrontation and Coping strategies are the reactions and behaviors one adopts to deal with difficult situation. Coping strategies come in many forms. Some are helpful and others are harmful. Multiple empirical studies show that significant changes in the life of an individual are connected with crisis experience and efforts made by individuals to adjust to new circumstances. Crisis life events are one of the most common topics in the area of research of basic determinants of psychological health because of the observed connection with the ways people function and adjust.

American social psychologists Richard Lazarus, Susan Folkman and others made considerable contribution to the development of models of crisis and coping in the late 19601970. They developed a theory of crisis and stress which emphasized appraisal and coping. Folkman defined coping as constantly changing cognitive and behavioral efforts to manage specific external and/or internal demands that are appraised as taxing or exceeding the resources of the person. It is important to note that in the process of coping a person can be guided by a number of important psychological functions. For example, there is self-esteem as a sense of control in life, a sense of meaning in life, personal growth, a sense of hope in life, feelings of intimacy and belonging with other people, a sense of personal identity and feelings of comfort in life.

To cut it short, coping is defined as the use of strategies for dealing with actual crises and their attendant negative emotions. The coping process involves every strategy of human function. Coping serves different purposes for different people dealing with different events in different contexts.
Many theorists agree that crisis experience is an antecedent of conversion that typically occurs under pressure. Crisis force individuals to confront their limitations and can stimulate religious resources to resolve problems, as says Pargament's theory.

People are often confronted by life experiences which result in crisis. These crises may have different sources and they vary in duration, intensity and scope.

Many theorists define crises as "crucial time" and turning point in the person's life. The term is often used for a person's internal reaction to external hazards. Hence, crises can be described as turning points in life, where the individual faces a problem that she/he cannot solve by using coping strategies that have worked for him/her before. A crisis may occur when individual is unable to deal effectively with stressful changes in the environment.

\subsection{Applied Research Contributions}

In 2010 Ozbay et al [5] presented a paper at the $31^{\text {st }}$ International Conference of the Stress and Anxiety Research Society (STAR) titled "An investigation of Coping and Psychological Symptoms of Earthquake Victims". The intended purpose of that study was to investigate coping experiences and psychological symptoms after a natural disaster. The central point of the study is that people who experience major distress and who do not are to cope with subsituations differently. The sample of the study was from the western part of Turkey, after the summer 1999 earthquake in the area. The study was in two sections. In section one, coping experiences and psychological symptoms of earthquake victims as well as the pattern of coping behavior and after effects were investigated in terms of psychological symptoms. In the second section, coping behaviors and psychological symptoms in those who have had earthquake experience and those who have not were compared. The sample consisted of 550 individuals of whom 270 were earthquake victims, and 280 were not. The results revealed that a major distress as earthquake made significant contribution for people to feel insecure and prone to psychological vulnerability. Regarding coping behaviors, more passive and Affectively tuned behaviors were dominant. A major finding of the study was that coping behaviors were decreased in earthquake victims and psychological symptoms of somatization interpersonal sensitivity, O-C phobic anxiety and paranoid ideation increased. Qualitative findings of the study were integrated and discussed with other findings in terms of a post -traumatic stress.

Across several decades many theorists contributed research in the area of coping with crises and conversion but they failed to find a common denominator for the two.

An example is Srdjan Sremac [6] who wrote in 2008 to evaluate theoretical approaches to coping with crisis and conversion, emphasizing the interdisciplinary approach. He assures that both coping and conversion are independent concepts and should not be confused. At the same time they are related phenomena.

Salehyan and Gelditsch [7] studied in 2006 the effects of 
crises of civil wars on migration, linking it to coping with crisis. They are research fellows of the center for the study of civil war at the International Peace Research Institute.

\section{Methodology}

In the current study, the descriptive method was used to cast light on Research problem through processes of data collection. This enabled us to describe the situation more carefully. In this context, hypotheses were not in a classical way. Rather Researchers included them in the objectives of the research. This served as a rationale for the criteria used for the purpose of interpreting the findings and for conclusions. In the analysis we relied on correlations as a statistical method by means of which the relationships between two or more variables were uncovered, indicating how the existence of a variable may be expected based on the existence of another.

\subsection{Participants}

The participants of the present study were 582 students from the Faculty of Education of Helwan University who were selected from different grades and departments. Their distribution is shown in table 1.

Table 1. Participants Distribution.

\begin{tabular}{llllllll}
\hline Male & Female & First grade & Second grade & Third grade & Fourth grade & Post graduate & Total \\
\hline 108 & 474 & 201 & 28 & 304 & 32 & 17 & 582 \\
\hline
\end{tabular}

\subsection{Procedures}

\subsubsection{A test of Coping with COVID-19 Crisis}

The resesrchers prepared this test to evaluate strategies of coping with the crisis. They reviewed testing theoretical background to understand this issue in a context of pandemic and epidemic disasters that usually affect large numbers of people. For example we reviewed works of Martin et al. [8]; Lazarus $\mathrm{R}$ and Folkman S [9]. also reviewed the serious life events and strategies of coping test of Arabic Researches.

\section{(i). Analyzing the Strategies of Coping with the COVID-19 Crisis}

Meant here is the group of positive procedures of dealing with this crisis. These procedures have three main strategies.

First is behavioral activation that takes place when people feel depressed or anxious. They may be less likely to do things they enjoy. Therefore, it is important to learn how to be more active.

Second is cognitive-behavioral coping strategy. These have been found to be effective for a wide range of symptoms that many people with post-traumatic stress disorder (PTSD) may experience such as depression, anger, sadness and anxiety.

The third is affective coping where no one is averted when personal tragedy strikes. The crisis is an inconvenience that is more than a minor accident. It may be a life-changing event such as the death of a beloved one. In such a context. Affective coping skills help a person manage intense feelings and physical stress that accompany such painful life transitions.

\section{(ii). Psychometric Properties of the Coping Test}

Test's validity was assessed. Where two major questions must be considered. First, whether the instrument can really measure the type of behavior that is meant to be measured. Second, whether it is applicable to an adequate sample that is assumed to accommodate that type of behavior. Simply, face validity is assessed by evaluators studying the concept to be measured and determining whether it is fit for its purpose.

\section{(iii). Factor Analysis}

The current researchers prepared an electronic version of the Test. After the assessment of its validity they applied it to the sample of 432 male and female students of the Faculty. Factor analysis was then carried out to identify clusters or groups of related items called factors. We verified sample sufficiency for factor analysis using the KMO (Kaiser Meyer - Olkin) technique. The parameter for significance was 0.738 . Thus, the sample was sufficient.

Kaiser criterion was used to estimate the basic factors, as an indicator of stopping or continuing to search for factors representing the basic structure. Reserchers kept the factors that the Eigenvalue, which included at least three statistically independent constraints. Varimax rotation applied of correlational matrix of measured strategy items to obtain an acceptable picture of the assessment, which enables us to interpret the factors accordingly.

Concluding from this criterion, Researchers excluded the items, which load less than 0.30. This included four items $(2.22 .25 .26)$.

Factor No. 1

Table 2 illustrates the loading items for this factor, where items are put in a descending order, from highest to lowest loading.

Table 2. Loading items of the first factor.

\begin{tabular}{lll}
\hline Item No. & Item Description & Item Loading \\
\hline 4 & My fear of getting infected makes me unable to think. & 0.709 \\
15 & Fear of the infection prevents me from living my normal life & 0.611 \\
12 & I am suffering from insomnia ever since I heard of COVID-19 & 0.545 \\
10 & Every time I follow the news of the spread of the infection. I panic & 0.53 \\
\hline
\end{tabular}




\begin{tabular}{lll}
\hline Item No. & Item Description & Item Loading \\
\hline 24 & I cannot study my lessons due to worrying about the virus & 0.519 \\
13 & I sleep a lot to avoid getting informed of the news about the spread of the virus & 0.508 \\
14 & I'm not following the news for fear of being surprised by a new crisis & 0.506 \\
9 & I get a tremor and disturbed whenever I hear about the numbers of people getting infected. & 0.48 \\
16 & I feel like I need a nerve-calming drug lately due to stress. & 0.416 \\
7 & I don't know if I can tell the difference between common flu and COVID-19 & 0.384 \\
11 & I'm worried when I imagine a member of my family carrying the virus. & 0.379 \\
3 & Negative ideas impacts my thoughts about the crisis that would not come to an end & 0.331 \\
Eigenvalue & & 3.583 \\
\multicolumn{2}{l}{ Variance percentage } & $13.78 \%$ \\
\hline
\end{tabular}

As seen in the table, this factor included 12 items revolving around ideas that can control thoughts about the possibilities of COVID-19 crisis. These ideas have effect on the ability to think about other things and throw doubt about the possibility of survival. They even distract the mind from thinking about infection by escaping defensive mechanism and other things. This factor can be called "cognitive dimension".

Factor No. 2
Loading items of this factor are presented in table 3 . As seen in the table, this factor included 5 items revolving around the behavioral procedures carried out by the individual in order to deal with the crisis. This is mainly collecting information through surfing on the Internet or by reading or observation of other sources, seeking advice to form a good knowledge background that enables a person to deal positively with the crisis.

Table 3. Loading items of second factor.

\begin{tabular}{lll}
\hline Item No. & Item Description & Item Loading \\
\hline 19 & I'm looking up information on the internet to help me deal with the crisis & 0.711 \\
20 & I read from different resources to know exactly what's new regarding the virus & 0.679 \\
17 & I seek advice from trusted sources on social media & 0.625 \\
1 & I'm looking into information about any crisis I'm going through & 0.539 \\
18 & I'm asking close friends for advice on my crisis & 0.521 \\
Eigenvalue & & 2.26 \\
Percentage variance & $8.69 \%$ \\
\hline
\end{tabular}

This factor included 5 items revolving around the behavioral procedures carried out by the individual in order to deal with the crisis, by collecting information through surfing on the Internet or by reading and seeing from other sources, seeking advice to form a good knowledge background that enables him to deal positively with the crisis, and can be called "behavioral dimension".

Factor No. 3

The items of this factor are presented in table 4 below.

Table 4. Loading factors items of the third factor.

\begin{tabular}{|c|c|c|}
\hline Item No. & Item Description & Item Loading \\
\hline 8 & I feel my heart beats a lot every time the name of the disease is mentioned & 0.331 \\
\hline 5 & I get obsessed that I am not going to survive this pandemic. & 0.391 \\
\hline 21 & I abide to security and safety measures & 0.582 \\
\hline 6 & I'm sure that God will respond to our prayers to end this crisis & 0.39 \\
\hline 23 & I repeat the words of reassurance ("everything will be good-you will get away well") & 0.382 \\
\hline \multicolumn{2}{|c|}{ Eigenvalue } & 1.76 \\
\hline
\end{tabular}

This factor contains 5 Items revolving around feelings associated with the sense of crisis. This is the appearance of physiological symptoms like palpitations and tremors or trying to feel self-reassurance by adhering to safety measures like praying and seeking spiritual support. or even by directing self-talk towards repeating expressions that give feelings of reassurance. This can be identified as the "Affective dimension".

\section{(iv). Internal Consistency of The Scale}

Internal consistency has been verified by assessing the strategies of coping with the crisis of the spread of the virus on a sample of (432), based on correlation coefficients, between each individual item and the strategy to which it belongs; each individual item and the Total scale; and between each strategy and the Total scale. All correlation coefficients were significant at the level of 0.01 as shown in the following tables.

For each factor, there are three tables for the correlation coefficients between the item and its dimension. And between the items and the Total scale. Then there is one table for the correlation coefficients between each strategy and the Total scale.

Correlations for the $1^{\text {st }}$ Factor "Cognitive dimension" 
Table 5. Correlation coefficients for the $1^{\text {st }}$ factor.

\begin{tabular}{llllll}
\hline Item No. & $\begin{array}{l}\text { Cor. Coeff. with the } \\
\text { dimension }\end{array}$ & $\begin{array}{l}\text { Cor. Coeff. with the Total } \\
\text { scale }\end{array}$ & Item No. & $\begin{array}{l}\text { Cor. Coeff. with the } \\
\text { dimension }\end{array}$ & $\begin{array}{l}\text { Cor. Coeff. with the } \\
\text { Total scale }\end{array}$ \\
\hline 3 & $* * 0.378$ & $* * 0.334$ & 12 & $* * 0.517$ & $* * 0.452$ \\
4 & $* * 0.602$ & $* * 0.583$ & 13 & $* * 0.415$ & $* * 0.378$ \\
7 & $* * 0.470$ & $* * 0.421$ & 14 & $* * 0.542$ & $* * 0.463$ \\
9 & $* * 0.525$ & $* * 0.451$ & 15 & $* * 0.589$ & $* * 0.472$ \\
10 & $* * 0.565$ & $* * 0.479$ & 16 & $* * 0.405$ & $* * 0.359$ \\
11 & $* * 0.488$ & $* * 0.331$ & 24 & $* * 0.557$ & $* * 0.460$ \\
\hline
\end{tabular}

** Significant at the level of 0.01

Correlations for the $2^{\text {nd }}$ Factor "behavioral dimension"

Table 6. Correlation coefficients for the $2^{\text {nd }}$ factor.

\begin{tabular}{lll}
\hline \multirow{2}{*}{ Item No. } & Cor. Coeff. & Cor. Coeff. \\
\cline { 2 - 3 } & with the dimension & with the Total scale \\
\hline 1 & $* * 0.554$ & $* * 0.263$ \\
17 & $* * 0.645$ & $* * 0.212$ \\
18 & $* * 0.574$ & $* * 0.206$ \\
19 & $* * 0.720$ & $* * 0.351$ \\
20 & $* * 0.670$ & $* * 0.298$ \\
\hline
\end{tabular}

** Significant at the level of 0.01

Correlations for the $3^{\text {rd }}$ Factor "Affective dimension"

Table 7. Correlation coefficients for the $3^{\text {rd }}$ factor.

\begin{tabular}{lll}
\hline \multirow{2}{*}{ Item No. } & Cor. Coeff. & Cor. Coeff. \\
\cline { 2 - 3 } & with the dimension & with the Total scale \\
\hline 5 & $* * 0.597$ & $* * 0.435$ \\
6 & $* * 0.491$ & $* * 0.242$ \\
8 & $* * 0.566$ & $* * 0.452$ \\
21 & $* * 0.553$ & $* * 0.152$ \\
23 & $* * 0.602$ & $* * 0.183$ \\
\hline
\end{tabular}

** Significant at the level of 0.01

\section{(v). Correlations between strategy and the Total scale}

This is to complete the assessment of internal consistency of the scale as previously explained. As seen in these tables, all coefficients of correlations were significant at the level of 0.01 . This indicates the coherence of the scale, its items and its dimensions. That is to say that the items of the scale are logical and consistent forming a unified Total.

Table 8. Correlations coefficient between strategy and the Total scale.

\begin{tabular}{ll}
\hline dimensions & Correlation Coefficient \\
\hline Cognitive & $0.845^{* *}$ \\
Affective & $0.510^{* *}$ \\
Behavioral & $0.420 * *$ \\
\hline
\end{tabular}

** Significant at the level of 0.01

\section{(vi). Reliability of The Scale}

The researchers calculated the reliability of the scale in two ways, the half-split correlation and the Alpha Cronbach statistic.

a. The Half-split Correlation

Applying the scale to the sample of 432 students, the halfsplit correlations between the two halves of the scale (pairindividual) were calculated using Guttmann equation and it was 0.503 . In comparison, the Spearman-Brown correlation between the two halves was 0.506 , which is almost the same.

b. The Alpha Cronbach Statistic

With the scale applied to the sample of 432 students, the Alpha Cronbach statistic for the whole scale was 0.674. This value means that the scale was highly reliable and stable.

\subsubsection{The Panic Test}

The Researchers used Panic disorder scale which prepared by Craske $\mathrm{M}$, et al. [10]. The Panic disorder scale was translated into Arabic by the researchers. The psychometric properties of this test were as follows.

\section{(i). Validity}

Validity was established by the peripheral comparison validation. This was calculated through an ascendant arrangement of student's scores on the panic scale and calculating $\mathrm{t}$ statistic of differences between averages of two equal peripheral groups. The highest and the lowest score groups consisting of 117 students each. which represents $27 \%$ of the sample. A statistically significant difference between the average grades of the two groups is evidence of the ability of the scale to distinguish between high and low performance and therefore is evidence that it is valid. This is shown in table below.

Table 9. Validity of the panic test.

\begin{tabular}{llllllll}
\hline Variable & group & number & mean & Std. Deviation & Df & t & Sig. \\
\hline \multirow{2}{*}{ Panic } & Highest & 117 & 8.12 & 1.018 & 232 & 44.645 & 0.01 \\
& lowest & 117 & 2.08 & 1.052 & 232 & \\
\hline
\end{tabular}

\section{(ii). Internal Consistency}

The internal consistency of the panic scale was verified on the same sample, based in the correlation coefficients between each individual item and the total score of the scale. All the correlation coefficient were significant at the level of 0.01 , which means that the scale has inner consistency. This is shown in table 10 .

Table 10. Inner consistency of the panic test.

\begin{tabular}{llll}
\hline Item No. & $\begin{array}{l}\text { Cor. Coeff. with } \\
\text { total score }\end{array}$ & Item No. & $\begin{array}{l}\text { Cor. Coeff. with } \\
\text { total score }\end{array}$ \\
\hline 1 & $0.593 * *$ & 6 & $0.330 * *$ \\
2 & $0.517 * *$ & 7 & $0.590^{* *}$ \\
3 & $0.511 * *$ & 8 & $0.545^{* *}$ \\
4 & $0.451 * *$ & 9 & $0.513^{* *}$ \\
5 & $0.561 * *$ & 10 & $0.375^{* *}$ \\
\hline
\end{tabular}

** Significant at the level of 0.01 


\section{(iii). Reliability}

Reliability of the panic test was ascertained by the halfsplit correlation method and Alpha Cronbach statistic. Using the sample of 432 students, the half split correlation between the 2 halves of the test, paired and individual, using Gutman equation was 0.714 and for the equation of long correction the Spearman- Brown correlation statisitc was 0.725. Using With these results, the test was highly reliable and stable.

\section{Findings}

COVID-19 outbreak is an unprecedented crisis for many people that is expected to generate stress throughout the population. Following are are the main findings of the study.

\subsection{The Prevalence of Suffering from Panic}

First. the score of 5 was taken as the level of cutting. Thus, a score higher than 5 was considered to be reflecting panic. The percentage of those who received a score higher than 5 defines how common was panic and fright among the students, which fulfils the first objective of this study. This is shown in table 11.

Table 11. The prevalence of suffering from panic.

\begin{tabular}{lll}
\hline Category & Number & Percentage \\
\hline Students with a score higher than 5 & 257 & 44.2 \\
\hline
\end{tabular}

As seen in the table, the proportion of students who were suffering from panic is $44.2 \%$. A similar result found in the United States of America where the prevalence of panic there, as reported by Resnick [11], was $46 \%$ among young people in the age of 18-29. It is also these young American the same sample, the Cronbach Alpha statistic was 0.699.

people were not most heavily impacted by the illness itself, but they felt extreme future uncertainty due to the economic crisis that could affect them negatively for decades.

\subsection{Differences on Panic Test Between Males and Females}

As to the difference between males and females in terms of panic, findings of the current research refer to a highly significant difference, where female students were much more in panic compared to male students. The average score of panic was 4.35 for males and 5.29 for females. The $t$ statistic for the difference was about 3.6, which is significant at the level of 0.01 as shown in table 12. Again. this result corresponds with the American data. This fulfills the second objective of the current research.

Table 12. Differences on the panic test between males and females.

\begin{tabular}{lllllll}
\hline Gender & N & Mean & Std. Deviation & df & T & sig \\
\hline Male & 108 & 4.35 & 2.357 & 580 & 3.602 & 0.01 \\
Female & 474 & 5.29 & 2.452 & & & \\
\hline
\end{tabular}

\subsection{Differences on Panic by Grade}

By Looking at the differences of reactions of students of different grades, there were no significant differences in terms of panic as shown in tables 13 and 14. Using analysis of variance, the differences among groups and between groups were insignificant based on the $\mathrm{F}$ test.

Table 13. Differences on panic by grade.

\begin{tabular}{llll}
\hline Grade & N & Mean & Std. Deviation \\
\hline First & 201 & 5.3 & 2.518 \\
Second & 28 & 5.07 & 2.538 \\
Third & 304 & 5.13 & 2.382 \\
Fourth & 32 & 4.09 & 2.441 \\
\hline
\end{tabular}

Table 14. ANOVA.

\begin{tabular}{lllll}
\hline Source of variance & Sum of squares & df & Mean Square & F \\
\hline Between Groups & 40.166 & 3 & 13.389 & 2.963 \\
Within Groups & 3345.402 & 561 & 5.963 & Not sig \\
Total & 3385.568 & 564 & & \\
\hline
\end{tabular}

This raises a question about stress in students' life in general regardless of COVID-19 . as Reddy K. J. et al.[12] found that feelings of stress are a part of university life due to different reasons. Such stress may have impact on panic meaning that more research is needed to analyze the position of Helwan University students. However, our finding fulfils the third objective of the current study.

\subsection{Correlations Between Panic and Coping Strategy}

To look at the strategies of coping, Table 15 showed a significant negative correlation between behavioral and cognitive strategy and the total score of panic. The relation is positive for the Affective strategy. This means that panic has a negative impact on coping such that when panic rises coping becomes weaker. The levels of significance varied between 0.01 and 0.05 . Such a negative relation was reported in the literature.
Table 15. Correlations Between Panic And Coping strategy.

\begin{tabular}{ll}
\hline Strategy & Correlation with Panic \\
\hline Cognitive & $-0.449^{* *}$ \\
Affective & $-0.099^{*}$ \\
Behavioral & $-0.240^{* *}$ \\
Total score of coping & $-0.292^{* *}$ \\
\hline
\end{tabular}

** Significant at the level of $0.01 *$ Significant at the level of 0.05

Tony Schwartz and Emily Pines [13], said that fatigue, fear and panic undermine our ability to clearly think and creatively manage our relationships effectively. The reason is that attention is focused on the right priorities to make smart and informed choices. The negative impact begins physiologically through allosteric regulation. which refers to the cost of chronic or extreme wear and tear on our bodies, minds and emotions. Allosteric overload occurs when demand on our internal resources exceeds our capacity. In addition. Ganesan et al [14] 
mentioned that coping strategy plays a significant role to overcome or reduce the stress experienced by individuals. Anyway, this finding fulfills the fourth objective of this study.

\subsection{Differences on Coping Strategies Between Males and Females}

The fifth objective is again about the difference between males and females, but now it is more specific. Previously the current researchers looked at the difference on panic generally and now we look at their differences on coping strategies. As shown in table 16. the differences are all insignificant, meaning that coping strategies are the same when attributed to gender. Taken at face value, this means also that nowadays Egyptian females have changing.

Table 16. Differences on Coping Strategies Between Students Males And Females.

\begin{tabular}{|c|c|c|c|c|c|c|c|}
\hline Strategy & Gender & $\mathbf{N}$ & Mean & Std. Deviation & df & $\mathbf{T}$ & sig \\
\hline \multirow{2}{*}{ Cognitive } & Males & 108 & 31.30 & 3.956 & \multirow{2}{*}{580} & \multirow{2}{*}{-1.718} & \multirow{2}{*}{ Not sig } \\
\hline & Females & 474 & 30.54 & 4.153 & & & \\
\hline Affective & Males & 108 & 13.91 & 1.156 & 580 & 0.269 & Not sig \\
\hline \multirow{2}{*}{ Behavioral } & Males & 108 & 9.52 & 2.684 & \multirow{2}{*}{580} & \multirow{2}{*}{-0.588} & \multirow{2}{*}{ Not sig } \\
\hline & Females & 474 & 9.37 & 2.310 & & & \\
\hline Total & Males & 108 & 55.58 & 5.167 & 580 & -1.653 & Not sig \\
\hline
\end{tabular}

All t statistics are insignificant

\subsection{The Effect of Human Development Training Course on Coping}

While this finding fulfills the objective, The Researchers are interested to think about variables that may affect such a change in females. They were aware of this possibility when they designed the research and first of all they thought that such change may be attributed to human developmental training. Thus the sixth objective was to find out the effect of human development training courses on coping and we studied it in both males and females. On data collection there was a question about attending such courses.

The surprise was that this proposed variable of change had no effect. The correlations between these courses and coping strategy were not only insignificant, meaning that they are ineffective, but were even negative.

Table 17. The effect of human development training course on coping.

\begin{tabular}{|c|c|c|c|c|c|c|c|}
\hline Strategy & Courses Received & $\mathbf{N}$ & Mean & Std. Deviation & df & $\mathbf{T}$ & sig \\
\hline \multirow{2}{*}{ Cognitive } & Yes & 85 & 30.62 & 4.293 & \multirow{2}{*}{580} & \multirow{2}{*}{0.142} & \multirow{2}{*}{ Not sig } \\
\hline & No & 497 & 30.69 & 4.100 & & & \\
\hline \multirow{2}{*}{ Affective } & Yes & 85 & 13.85 & 1.500 & \multirow{2}{*}{580} & \multirow{2}{*}{0.195} & \multirow{2}{*}{ Not sig } \\
\hline & No & 497 & 13.88 & 1.389 & & & \\
\hline \multirow{2}{*}{ Behavioral } & Yes & 85 & 9.98 & 2.435 & \multirow{2}{*}{580} & \multirow{2}{*}{-2.437} & \multirow{2}{*}{0.05} \\
\hline & No & 497 & 9.30 & 2.361 & & & \\
\hline Total & Yes & 85 & 55.25 & 4.952 & 580 & -0.777 & Not sig \\
\hline
\end{tabular}

$\mathrm{t}$ statistic is significant only for the behavioral strategy at the 0.05 level

As shown in table 17, $\mathrm{t}$ statistics of the correlation for the cognitive and the affective strategies were in significant. It was significant only for the behavioral strategy at the level of 0.05 but the correlation was negative. Positive correlations were there for the other two strategies, but were insignificant.

Thus. the sixth objective of the study is fulfilled but obviously, we need to interpret the observed change in female coping. This is to be addressed in further research.

\subsection{The Overall Effect of Human Development Training, on Panic}

In order to confirm this finding, the overall correlation coefficient was calculated for human development training courses and the level of coping regardless of coping strategy. The correlation was highly significant with a negative sign. This is shown in table 18 .

Table 18. The overall effect of human development training on panic.

\begin{tabular}{lllllll}
\hline Receiving courses & N & Mean & Std. Deviation & df & t & Sig \\
\hline yes & 85 & 6.26 & 2.416 & 580 & -4.731 \\
No & 497 & 4.92 & 2.415 & 0.01 & \multirow{2}{*}{5} \\
\hline
\end{tabular}

\subsection{The Effect of Social Media Psychological Services on Panic}

Still interesting is the possible effect of psychological services presented on social media on the level of panic. This is the seventh objective of this research. Finding out if there is such effect, Researchers compared average panic scores of two sub-samples of students who were and who were not 
exposed to social media. There was a highly significant effect and it was negative. This negativity should mean that the more youth follow social media getting from it psychological services the less they feel panic. This is shown in table 19.

Table 19. The effect of social media psychological services on panic.

\begin{tabular}{lllllll}
\hline Exposure to Social Media & N & Mean & Std. Deviation & df & Sig \\
\hline Exposed & 299 & 5.73 & 2.266 & \multirow{2}{*}{580} & -6.381 \\
Not Exposed & 283 & 4.47 & 2.494 & 0.01 \\
\hline
\end{tabular}

\subsection{The Effect of Social Media Psychological Services on Coping}

Further to investigate the effect of social media on coping. Results showed that there were statistically significant differences in coping between the average scores of the students who were exposed to social media getting online psychological services and those who were not exposed and did not get such services. This is shown in table 20 .
This fulfills the seventh objective of this study and in the meantime, it is opposite to the observation of many researchers who found that social media is responsible for the spread of panic. Examples are Ahmad and Murad [15], and Depoux et al [16]. Social media may have different contents in different countries, and therefore may produce different effects on users in different countries. May be Social media in Egypt was pacifying for its users.

Table 20. The effect of social media on coping.

\begin{tabular}{|c|c|c|c|c|c|c|c|}
\hline Strategy & Type of Followers of Social media & $\mathbf{N}$ & Mean & Std. Deviation & df & $\mathbf{T}$ & Sig \\
\hline \multirow{2}{*}{ Cognitive } & Who follow social media & 299 & 30.98 & 3.91 & \multirow{2}{*}{580} & \multirow{2}{*}{-1.794} & \multirow{2}{*}{ Not sig } \\
\hline & Whom don't' & 283 & 30.37 & 4.325 & & & \\
\hline \multirow{2}{*}{ Affective } & Who follow social media & 299 & 13.99 & 1.352 & \multirow{2}{*}{580} & \multirow{2}{*}{-2.043} & \multirow{2}{*}{0.05} \\
\hline & Whom don't' & 283 & 13.75 & 1.45 & & & \\
\hline \multirow{2}{*}{ Behavioural } & Who follow social media & 299 & 9.71 & 2.452 & \multirow{2}{*}{580} & \multirow{2}{*}{-3.312} & \multirow{2}{*}{0.01} \\
\hline & Whom don't' & 283 & 9.06 & 2.264 & & & \\
\hline Total & Whom don't' & 283 & 54.09 & 5.223 & 580 & -3.485 & 0.01 \\
\hline
\end{tabular}

As seen in the table, there is generally a negative effect. The total effect and the effect on the behavioral strategy were both significant at the level of 0.01 . The effect on the affective strategy was significant at the level of 0.05 , the effect on the cognitive strategy was insignificant. The effect on the behavioral and the affective strategies means that social media is a source of information but the negative relation indicates that may not be trusted.

\subsection{The Possibility to Predict the Level of Coping by the Level of Panic}

The last objective of this study was to check for the possibility to predict the level of coping if the level of panic is known. A causal relation is supposed here, which can be examined by a regression analysis. A simple linear regression was run with panic as the independent variable, in the form of the known equation: $y=a+b x$, where $y$ is the dependent variable "coping", $\mathrm{a}$ is the regression constant and $\mathrm{x}$ the independent variable "panic". The result is shown in table 21 and table 22.

These tables show that we can predict the score of style of coping by knowing the score of panic because the value of $\mathrm{F}$ is (54.128). This value is significant $(0.01)$ hence, this table has shown that the independent variable (panic disorder) interpret (85\%) from the discrepancy in independent variable (style of coping). We can form the regression equation which helps to predict of scores of coping styles from the scores of panic disorders as follows: Coping $(-0.610)$ and Panic Disorder $(+57.966)$.

Table 21. Simple linear regression of coping on panic.

\begin{tabular}{lllll}
\hline Independent variable & Constant & b & R $^{\mathbf{2}}$ & \\
\hline Panic & 57.966 & -0.292 & 0.084 & -0.61 \\
\hline
\end{tabular}

Table 22. Variant analysis.

\begin{tabular}{lllll}
\hline Source of Discrepancy & Sum of Squares & Degrees of freedom & Median Squares & F \\
\hline Regression & 1307.816 & 1 & 1307.816 & 24,128 \\
Remainders & 14013,574 & 580 & 24,161 & 0 \\
Total & 15321,390 & 581 & 0 & 0,01 \\
\hline
\end{tabular}

\section{Conclusions and Recommendations}

We should admit that the panic scores were normal for some students and some were suffering from high anxiety and panic. Actually, some students with pre-existing mental health conditions disorders may particularly be vulnerable. We may admit that vulnerability is a result of conditions like anxiety and bipolar disorder. The latter in particular affects a person's thinking, feeling, mood and behavior in a way that 
influences the ability to function in everyday life. Hence every individual reacts differently to stressful situations. In addition, there is observed higher panic in female than male.

With these results we recommend further research about the same subject. In other words there is a need for a series of studies that can provide better explanation of panic so that real support can be provided for students and for others in terms of mental and psychological well-being. Researchers may investigate the following.

1. Effective resilient focused leadership that empowers people.

2. Leadership may develop optimistic focused vision and realistic plan B.

3. Empowering information may bring rational ideas and hope vs chaos and ambiguity.

4. Researchers should use qualitative techniques to investigate the negative psychological impact of crises and disasters. This may allow more understanding and in depth analysis.

\section{References}

[1] Jarus, Owen (2020). 20 of the Worst Epidemics and Pandemics in History, retrieved from the Internet at: https://www.livescience.com/worst-epidemics-andpandemics-in-history.html.

[2] WHO (18 March 2020). Mental health and psychosocial considerations during the COVID-19 outbreak, retrieved from the Internet at: https://www.who.int/docs/defaultsource/coronaviruse/mental-healthconsiderations.pdf?sfvrsn $=6 \mathrm{~d} 3578 \mathrm{af} \_10$

[3] Clarke, D. M. (1986). A Cognitive Approach to Panic. Behaviour Research and Therapy. 24: 4, pp 461-470.

[4] Barlow, D. H. (1988). Anxiety and its disorders: The nature and treatment of anxiety and panic. New York: Guilford Press.

[5] Ozbay, Y. et al (2010). An investigation of Coping and Psychological Symptoms of Earthquake Victims. $31^{\text {st }}$ International Annual Conference of the Stress and Anxiety Research Society (STAR), Galway, Ireland, August 2010.

[6] Sremac, S. (2008). "Theoretical approaches to coping with crises and conversion". Religion and Tolerance, 6 (10), 55-70.
[7] Salehyan, Idean and Kristian Skrede Gleditsch (2006). Refugees and the Spread of Civil War, Retrived from the Internet. https://doi.org/10.1017/S0020818306060103

[8] Martin, P., Lee, H. S., Poon, L. W., Fulks, J. S., (1992). Personality, life events and coping in the oldest-old. International Journal of Aging \& Human Development, 34 (1), Pp 19-30.

[9] Lazaruse, R and Folkman, S (1984). Stress, Appraisal and Coping. New Yourk: Springer Publishing Company. INC.

[10] Craske M, Wittchen U, Bogels S, Stein M, Andrews G, Lebeu R. (2013). Severity Measure for Panic Disorder. American Psychiatric Association. http://www.appi.org/CustomerService/Pages/Permissions.aspx

[11] Resnick, B. (2020). A third of Americans report anxiety or depression symptoms during the pandemic. Young adults are experiencing the highest rates of mental health strain during the pandemic, according to new CDC data. May 29, 2020. https://www.vox.com/science-andhealth/2020/5/29/21274495/pandemic-cdc-mental-health.

[12] Reddy K. J, Menon K. R, Thattil A. (2018). Academic Stress and its Sources Among University Students. Biomed Pharmacol J, 11 (1). Available from: http://biomedpharmajournal.org/?p=19485.

[13] Tony Schwartz and Emily Pines (2020). Coping with Fatigue, Fear, and Panic During a Crisis, Harvard Business Review, March 23, 2020. Retrieved from the Internet at: https://students.pharmacy.wisc.edu/wp-

content/uploads/Coping-with-Fatigue-Fear-and-Panic-Duringa-Crisis-HBR-2020.pdf

[14] Ganesan Y. Talwar P. Norsiah Fauzan and Oon Y. B. (2018). A Study on Stress Level and Coping Strategies among Undergraduate Students. Journal of Cognitive Sciences and Human Development. Vol. 3 (2), 37-47.

[15] Ahmad, A. Ramzan and Hersh R. Murad (2020). The Impact of Social Media on Panic During the COVID-19 Pandemic in Iraqi Kurdistan: Online Questionnaire Study, Journal of Medical Internet Research, Volume 22; doi: 10.2196/19556.

[16] Depoux, A.; S. Martin; E. Karafillakis; R. Preet; A. WilderSmith and H. Larson (2020). The pandemic of social media panic travels faster than the COVID-19 outbreak, Journal of Travel Medicine, Volume 27 (3). Retrieved from the Internet. https://doi.org/10.1093/jtm/taaa031 